\title{
REFLEXIONES DE UN ESPAÑOL SOBRE \\ LA INDEPENDENCIA DE LA AMÉRICA LATINA: JOSÉ Mª BLANCO WHITE*
}

\author{
José Martínez de Pisón Cavero
}

CATEdRÁtico de Filosofía del DeReCho

UNIVERSIDAD DE LA RIOJA

\author{
Excmo. Sr. Rector Magnífico \\ Excmas. e Ilustrísimas Autoridades \\ Miembros del Claustro Universitario \\ Señoras y señores
}

La concesión del Doctorado Honoris Causa es el más alto honor que puede recibir un profesor de una institución universitaria. El que, además, las enseñas y los símbolos sean entregados por un Rector ilustre como es el de la Universidad Nacional de Piura, D. Antenor Agüera, colma la satisfacción de todo universitario. De ahí que mis primeras palabras de esta lección de investidura sean de agradecimiento al Rector, al Director de Relaciones Internacionales, al Decano y la Facultad de Ciencias Jurídicas de la Universidad Nacional de Piura, y de satisfacción por el honor recibido, sin duda, la más alta distinción que un universitario puede desear. Este acto, además, muestra las magníficas relaciones de colaboración existentes entre la Universidad Nacional de Piura y la Universidad de La Rioja iniciadas ahora hará unos dos años. Aprovecho la oportunidad para aventurar que en el futuro estas relaciones seguirán mejorando sin duda.

Se cumplen en el 20I0 los doscientos años de los inicios del movimiento emancipatorio de la América Latina que conduciría unos dos lustros más tarde a su independencia de la monarquía española. La historiografía hace tiempo que ha estudiado y

\footnotetext{
* Discurso leído por D. José Ma Martínez de Pisón, Rector de la Universidad de La Rioja, en la concesión del Doctorado Honoris Causa por la Universidad Nacional de Piura (Perú).
} 
glosado con rigor las etapas, las áreas geográficas, los hechos, las personalidades de los personajes, los datos más relevantes de un proceso complejo e inevitable ${ }^{\mathrm{I}}$. Así, se acepta en buena medida que en la independencia americana de España existieron dos fases bien delimitadas: la de I8ı a I8I5 y la de I8I6 a I824. La primera correspondería a las primeras revueltas focalizadas principalmente en Caracas y Buenos Aires y que se extendieron por la geografía latinoamericana hasta que, reinstaurado en I8I4 Fernando VII como monarca absoluto de España, el envío de tropas de la península restablecería el viejo orden colonial, aunque fuera por poco tiempo. En efecto, las fuerzas patriotas se reorganizarían e iniciarían una nueva fase bélica que concluiría en la independencia de las colonias españolas en América, principalmente tras las victorias de Simón Bolívar en Junín y de Sucre en Ayacucho, ambas en terreno del Perú.

La impartición de la lección en la investidura del Doctorado Honoris Causa por la Universidad Nacional de Piura (Perú) me ha parecido una excelente oportunidad para recordar y conmemorar estos hitos históricos para América Latina y, en particular, para el Perú y para España. Mi intención no es hacerlo como una mera glosa histórica, pues, como he afirmado hace un momento, ésta está hecha ya. Me interesa, más bien, mostrar ante este inteligente auditorio cómo fueron percibidos estos acontecimientos históricos a través de la mirada y el pensamiento de uno de los españoles más brillantes, lúcidos e inteligentes y, al mismo tiempo, olvidado y repudiado de la España de inicios del siglo XIX. Me refiero al sevillano José $\mathrm{M}^{a}$ Blanco y Crespo, más conocido como Blanco White, tanto por el origen irlandés de su familia como por su largo exilio en Inglaterra en donde trocó el apellido al habla de Shakespeare ${ }^{2}$.

José María Blanco White nace en Sevilla un is de julio de I775 y muere en Liverpool el 20 de mayo de I84I. Aunque durante muchas décadas fue un auténtico desconocido en su tierra, lo cierto es que, en los últimos tiempos, la reivindicación de su figura es ya un hecho. Es más, para algunos es el escritor, pensador, teólogo y periodista español más importante de la primera mitad del siglo XIX. Destinado desde muy joven al sacerdocio, sin embargo, su personalidad se nos aparece plena de inquietudes y contradicciones que le llevaron siempre a buscar la verdad tanto de las cosas humanas como divinas. Precisamente, esto mismo le llevó a renunciar pronto a la religión materna, a la Iglesia católica, para convertirse al anglicanismo y, finalmente, recalar en el seno del unitarismo.

El año i808, como para muchos de esa generación, fue un año crucial para Blanco White. La entrada del ejército francés en la península y la posterior revuelta del pueblo español marcarán de forma indeleble la vida de mucha gente. Para muchos intelectuales formados en el pensamiento de la Ilustración fue también el momento de aprovechar la llamada «revolución española» para cambiar la estructura política y social del país y para hacerlo democráticamente a través de la institución de las Cortes.

I8Io fue, además, para Blanco White un año trascendental, pues, invadida Sevilla y asediado Cádiz por las tropas francesas, decide exiliarse en Inglaterra, tierra de la libertad y del pensamiento, donde pronto acabaría renunciado al sacerdocio católico e iniciaría su progresión como periodista y pensador. En efecto, al poco de desembarcar en Londres, tuvo la oportunidad de iniciar una aventura periodística con la edición del periódico El Español. Ya en I809, en Sevilla, había dirigido otro llamado El Semanario Patriótico que informaba de los acontecimientos políticos y militares de la guerra. En Londres, su amistad con Lord Holland y sus contactos con el Foreign Office le permitieron acceder a un información clave sobre la situación en España. El Español, que inició su andadura en i8ıo para cerrarlo de i8I4 con la restauración de Fernando VII, se convirtió así en una importante fuente de

\footnotetext{
'M. Hernández Sánchez-Barba, Historia de América, 3 vols., Madrid, Alhambra Universidad, I98I.

${ }^{2}$ Baso buena parte de la lección en mi estudio J. Martínez de Pisón, José Ma Blanco White. La palabra desde un destierro lúcido, Logroño, Perla Ediciones, 2009.
} 
información para España y para Latinoamérica al tiempo que le permitió desarrollar su pensamiento político y social y demostrar un gran conocimiento histórico y literario.

Pronto se interesó por los avatares y sucesos de la América Latina o, según su expresión, por las cosas de «los españoles de América», quienes en «la otra España libre» necesitaban «nuestros consejos». De hecho, en Londres hizo grandes amistades con intelectuales procedentes de estas tierras. El caso más claro es el del venezolano Andrés Bello quien vivió en Londres desde I8Io a I829 coincidiendo, por lo tanto, con Blanco White quien, a su vez, lo introdujo en el importante círculo de su amigo Lord Holland. Producto de este interés fue también la divulgación de la obra del Abate Viscardo, jesuita de Arequipa, muerto en Londres en I789, quien fuera un apasionado de la libertad de América. El general «libertador» Miranda fue precisamente un defensor de sus teorías en su correspondencia con Blanco White. Finalmente, ya pasados unos años, el autor sevillano dedicó unas importantes páginas al libertador por excelencia, Simón Bolívar, en otra experiencia como editor, en este caso, del periódico Variedades o el Mensajero de Londres dirigido principalmente al ámbito latinoamericano3. Estamos ya en el año I824 cuando la independencia es un hecho, pero no dejó de realizar una afirmación clarividente: «No hay guerras más crueles que las que se hacen entre pueblos de un mismo origen, pero tampoco las hay más abundantes en hechos de valor heroico». Y concluye su escrito sobre Bolívar con un aserto lleno de incógnitas: «A nadie, empero, deben más que al hombre extraordinario de cuya carrera pública hemos dado un bosquejo. Su valor, su firmeza en los reveses, su prontitud en las decisiones, y los talentos militares que ha mostrado le han adquirido justamente el nombre de segundo Washington. Ojalá acierte a imitar la moderación de su gran modelo en medio de la prosperidad que empieza a despuntar sobre los países que le deben su independencia» ${ }^{4}$.

\section{III}

Más allá de otras disquisiciones sobre el interés de Blanco White por América Latina, lo cierto es que prontamente fijó su atención en la relación entre la metrópoli y las colonias allende el Atlántico. Todavía en Sevilla y por encargo de su Universidad elaboró un «Dictamen sobre el modo de reunir las Cortes de España» en donde trató de forma original la participación americana en esta institución. Eran tiempos difíciles, pues la ciudad estaba asediada y, al poco, tuvo que huir a Cádiz sin conocer la repercusión de su escrito en la mente de los convocantes. Con el tiempo se vería que no le hicieron mucho caso. Craso error.

En el debate sobre cómo convocar las Cortes -al modo antiguo, medieval, o al modo moderno-, fue muy explícito. Junto a interesantes reflexiones sobre las «cortes antiguas», la situación de la guerra -«la patria en peligro»- y la necesidad de la convocatoria de las Cortes, señala en este escrito que más tarde publicaría en El Español, que «la nación española debe ser representada según las reglas generales que la razón dicta cuando se trata de semejantes congresos». Y la razón dicta que, en el momento trágico de la nación, con sus propios fundamentos en juego, no se debe atender a privilegios, ni a «leyes constitucionales de cortes antiguas», que «no son claras ni equitativas».

De ahí, extrae Blanco White una tesis, sin duda, revolucionaria para su tiempo: que «la nación española empezó a existir de nuevo cuando, abandonada de sus autoridades, se rescató de las manos del usurpador extranjero». Como consecuencia, se rompieron todos los lazos políticos existentes hasta entonces «y sólo conservó, porque quiso, sus relaciones

\footnotetext{
${ }^{3}$ M. Moreno Alonso, Blanco White. La obsesión de España, Sevilla, Ediciones Alfar, 1998.

${ }^{4}$ J. M. Blanco White, Conversaciones americanas $y$ otros escritos sobre España $y$ sus Indias, edic. de M. Moreno Alonso, Madrid, ICI, I993, págs. I65-I74.
} 
con el desgraciado rey Fernando». Ante la situación sobrevenida, no valen pues las leyes antiguas, ni los vínculos y sujeciones seculares. Como cualquier situación nueva, requiere soluciones nuevas. Y ésta no es otra que convocar Cortes en igualdad de condiciones, los españoles de España y los españoles de América. Como dice, «las cortes que han de celebrarse son un efecto de esta inmortal reconquista, háganse pues como se empezó ella: mezclados todos como patriotas, unidos todos como españoles».

He ahí la recomendación de Blanco White ante la consulta de la Universidad de Sevilla: convóquense Cortes, no al modo antiguo, sino al modo moderno en el que todos los españoles -de Europa, de América y de África- sean iguales. Son tiempos en los que todavía no se había iniciado el movimiento emancipatorio. Pero anticipa ya los problemas que surgirán con la extensión del problema político a las colonias americanas. De ahí que el remedio no podía ser el retorno a los vínculos antiguos; por el contrario, la representación en Cortes debía ser proporcional entre la metrópoli y las colonias y debía inspirarse en la igualdad de trato.

\section{IV}

Los siguientes números de El Español editados a lo largo de ı8ıo verán cómo la cuestión americana crece en interés e importancia tanto en la descripción de los sucesos, de la revolución en las colonias, como en la exposición de la postura de Blanco y en las réplicas y críticas que recibe. No dejó de recoger también las opiniones de quienes contradecían sus puntos de vista. En suma, constituyen un interesante relato de los acontecimientos, la postura de los protagonistas y la exposición de los documentos oficiales generados por la nueva situación. Finalmente, el autor sevillano elaborará y publicará en el periódico unas originales Conversaciones americanas sobre España y sus Indias en donde volverá a plasmar las diferentes posturas y procurará reforzar su tesis principal. Merece la pena leer este escrito estructurado al modo de un diálogo platónico, aunque, desgraciadamente, apenas podré referirme a él en mi intervención.

La primera noticia de los nuevos acontecimientos americanos apareció en el número de julio de i8io de El Español en el que se describe la revolución de Caracas, acompañadas de unas interesantes reflexiones del editor. Desde luego, la descripción de la «revolución de Caracas», tal y como aparece en este número de El Español, no deja mucho margen a la duda sobre las intenciones de sus promotores, en principio, no muy diferentes a las de la península. Según Blanco White, todo se inicia cuando, el ig de abril de ı8ıo, «la tropa tomó el partido del pueblo desde el primer momento. Confiose la administración de los negocios públicos a una Junta, con el título de Suprema, entretanto que se recogieran legalmente los votos de toda la provincia para la formación de su gobierno». Se instaura, pues, un nuevo gobierno que publica un manifiesto en el que da detalles sobre la desgraciada marcha de la guerra en Andalucía y la penosa situación de la metrópoli. Su objetivo era ponerse a salvo de las pretensiones de otros países y de las intrigas del gobierno francés para lo que ratifica su lealtad a la Corona española, promete auxilios a los peninsulares y, en su caso, asilo. Al mismo tiempo, toma las primeras medidas liberadoras que afectan principalmente a la supresión de impuestos. Precisamente, estos pronunciamientos son los que conducen a Blanco White a referirse a la moderación del movimiento, aunque no parezca que prestara mucha atención a este último aspecto muy importante para los comerciantes gaditanos.

En las «Reflexiones Políticas sobre América» que siguen a la descripción de la revolución de Caracas, Blanco White deja traslucir la importancia de los acontecimientos de los que está dando noticia: «Parece que ha llegado la época de un gran acontecimiento político, que se ha esperado por largo tiempo: el estandarte de la independencia se ha empezado a levantar en América, y según podemos calcular, por lo que hemos visto acerca de la revolución de Caracas, no es un movimiento tumultuario y pasajero el de aquellos 
pueblos, sino una determinación tomada con madurez y conocimiento, y puesta en práctica bajo los mejores auspicios, la moderación y la beneficencia». Esto es, el movimiento iniciado en Caracas no debiera extrañar dadas las transformaciones que atravesaban Europa y América desde finales del siglo XVIII. En esos tiempos, la llama de la libertad debería prender en algún momento, y la ausencia del monarca Fernando VII y la invasión francesa de la península eran el contexto propicio para que finalmente se encendiera y propagase. Nótese que Blanco White es bien consciente de que el movimiento no es «tumultuario y pasajero», sino que está bien madurado y que, en consecuencia, no será fácil el reintegro a la situación anterior una vez que se requiere unas nuevas relaciones entre la metrópoli y las colonias.

Estas primeras reflexiones, que van acompañadas de una recapitulación final en las últimas páginas del número de El Español, muestran la cautela con la que Blanco White analiza los objetivos de los revolucionarios y, al mismo tiempo, un análisis inteligente de los riesgos para la Corona española en el caso de que no se tomen las decisiones pertinentes y, sobre todo, no se tomen en serio la nueva situación con una perspectiva y unas medidas diferentes a las tradicionales. Es, en este sentido, en el que sus reflexiones rezuman simpatía por los luchadores por la libertad de América. Como se ha escrito, «para Blanco era evidente que Venezuela -tras la revolución de Caracas- engrosaba el número de las naciones libres de América. A partir de este foco, El Español señalaba que la 'revolución total' de América era muy probable...» (Moreno Alonso I998: 220).

Con todo, Blanco White no ve si no el lado positivo del primer movimiento emancipatorio. Así pues, no se trata de una revolución que proclama los «principios exagerados de libertad, teorías impracticables de igualdad como las de la revolución francesa». Por el contrario, «la proclama de Venezuela respira amor a los españoles: éste es inextinguible en los americanos». En suma, de lo que se trata es, igual que en la península, de «formar un gobierno interino durante la ausencia del monarca, o en tanto que no se establezca la monarquía sobre nuevas y legítimas bases». Se trata de liberarse de las cadenas de los gobernantes tiranos del momento, de los virreyes, para poder destinar nuevos recursos contra el invasor. «Las Américas -afirma Blanco White-, libres del yugo en que se las ha querido y quiere tener tan imprudentemente todavía, serán infinitamente más poderosas para mandar recursos a España, y los americanos no necesitarán de dependientes del fisco para auxiliar abundantemente a sus infelices compatriotas de Europa».

En todo caso, Blanco insiste todavía en I8ıo en la moderación de este primer movimiento del que destaca «los sentimientos de fidelidad al soberano y adhesión a la metrópoli». De lo contrario, los riesgos son evidentes, pues, sigue afirmando, «según las noticias, la revolución se ha extendido desde Cartagena al Brasil; La Habana parece que toma medidas políticas, independientemente de toda autoridad europea. La revolución total de América es muy probable, y sólo apetecemos que sus pueblos guarden la moderación de Caracas: Fernando VII rey; unión de amistad $y$ socorros a la metrópoli. Bajo estos principios la revolución es gloriosa, en las actuales circunstancias; es un golpe funesto a Bonaparte».

A lo largo del año ı8ıo, el periódico El Español, editado exclusivamente por Blanco White, no dejó de dar noticias sobre los hechos de América. Son muchas sus preocupaciones y algunas resaltan sobre otras: la integridad de la monarquía española, la libertad de comercio, la cuestión de la esclavitud, el papel de Inglaterra como mediadora entre metrópoli y colonias y, sobre todo, la labor de las Cortes. También hay que mencionar a la constante defensa de una posición que no era bien entendida en la península, ni siquiera por sus amigos, y que le condujo a la condena pública. ¡Las Cortes, incluso, llegaron a repudiarlo al mismo nivel que el emperador francés! 
Su postura, sin embargo, se sostenía en un difícil equilibrio. En el número de agosto de i8ıo, Blanco White publica un escrito que es un claro reflejo de sus dificultades. El artículo lleva un título muy significativo: «Integridad de la Monarquía Española». En él, desde una posición de observador imparcial, analiza y da consejos a una y otra parte. A los españoles de América les dice que «la reforma -se refiere a la transformación del vínculo entre uno y otro lado del Atlántico- es excelente y saludable, en tanto no rompa los diques que el orden establecido opone a estas pasiones encontradas; y que esta reforma se debe hacer con todo tino y conocimientos que requiere la renovación de un edificio». Por su parte, continúa, «los españoles de Europa deben tener presente que la fuerza jamás produce buenos efectos sobre los pueblos, y mucho menos cuando por ser ésta débil, sólo puede lograr irritarlos... La América toda fermenta, ¿no valdrá más dirigir la inundación que dejar que rompa sin dirección por muchas partes a un tiempo? ¿No valdrá más añadir el nuevo lazo de respeto y agradecimiento que esta conducta añadiría, que exponerse a ser mirados como émulos, y a estar expuestos a convertirse en enemigos?». Finalmente, Blanco White apunta lo que considera la receta imprescindible para salir del conflicto: «la igualdad de derechos que han reasumido ya parte de los americanos» y la renuncia de España «a toda pretensión de superioridad sobre aquellos países, y convidarles a que (los que no lo hayan hecho) nombren sus gobiernos interiores y económicos, y en seguida envíen sus diputados al congreso de ambos mundos».

En el número de noviembre de i8ıo, Blanco White sigue con sus «Reflexiones sobre la cuestión de América» y vuelve a insistir en la clave de la crisis política: «Si las Américas son provincias de España -tal y como la se había proclamado por real orden de 22 de enero de I809-, iguales deben ser con ellas en derechos, sean cuales fueren las consecuencias». Y ello no es contrario a los intereses de la monarquía españolas. Además, «la determinación de una parte de América está ya bien manifiesta. Cual más cual menos, todos los pueblos que han hecho mudanza de gobierno han manifestado que se quieren separar de España, que quieren ser vasallos de Fernando VII, pero como lo son los europeos que pertenecen a su corona». De ahí el único remedio: «Equidad y equidad absoluta, es el único lazo que queda entre uno y otro pueblo; más diré, entre los mismos pueblos de América». Igualdad de derechos, por tanto, e igualdad en la representación en las Cortes.

Con el tiempo, y a la vista de la experiencia de la independencia de Estados Unidos de Inglaterra, Blanco White aventuró incluso una solución mucho más moderna que, si bien no fue atendida por la monarquía española, paradójicamente, sirvió para la pervivencia del imperio inglés durante el siglo XX. Y es que el autor sevillano pensó que la igualdad de derechos entre unos y otros debería plasmarse en una Commonwealth regida por el monarca español. La historia ha mostrado que la experiencia fue por derroteros bien distintos.

\section{VI}

Desde el primer momento, Blanco White fue partidario de la convocatoria a Cortes, institución en desuso en la España de los Borbones, pero que no dejaba de tener un cierto aire democratizador si se orientaban adecuadamente. De ahí que viera con esperanza su constitución y el inicio de sus labores. El periódico El Español recogerá en sus páginas una crónica atenta a la tarea encomendado a las Cortes y analizará detenidamente sus resultados. No obstante, con el paso del tiempo, la actitud de Blanco White irá cambiando hasta la desesperación a la vista de sus, en su opinión, errores y falta de operatividad para resolver los problemas políticos, sociales y militares provocados por la guerra contra Francia. Una parte importante de su atención se dirigirá también a la postura de las Cortes respecto al conflicto americano.

En efecto, la discusión de la cuestión americana en las Cortes ubicadas en Cádiz fue una excelente oportunidad para reiterar su opinión. Pero en una actitud muy española, las Cortes se dedican a realizar grandes declaraciones y, en opinión de Blanco White, no 
afrontan el problema de verdad, y si toman decisiones siguen cometiendo los errores de la Junta Suprema y de las Regencias anteriores. Así, afirma: «los discursos sobre la cuestión de América están llenos de excelentes principios; pero pasma el considerar cuán inútiles son en la práctica, y cuán lejanos del objeto que más importa a la España en el día -la conservación de las Américas-, la cesación de la guerra civil entre ellas. Y lo que es más de admirar, casi todos los diputados han hablado de este objeto; mas como si una especie de vértigo los distrajera al instante siguiente no bien les hiere los ojos, cuando los vuelven a otra parte, y se pierden en un laberinto de cuestiones abstractas».

«Cortes filosóficas, Cortes inoperantes», serán las dos grandes acusaciones que el sevillano lanzará sobre una institución que había levantado tantas expectativas. colonial:

En una larga cita, se resume el grito desesperado de quien vaticinaba el desastre

«La cuestión no es ya ¿cuánto influjo se ha de dar a la América en las Cortes? Es solamente ¿cómo se les ha de hacer concurrir cordialmente a ellas sin valerse del medio indigno, destructivo y dudoso de las armas? Es decir ¿cómo ha de disfrutar España del poder que le puede comunicar la América, sin hacer en ella la guerra, sin obtenerlo de un modo precario, y sin perjudicarse a sí, ni a aquellos países, a sí en las presentes críticas circunstancias y a ellos ni en las presentes ni futuras, como lo exige la justicia?

Presentado como, sin duda se debe mirar el problema, resta hallar un medio que lo resuelva. Las condiciones de la medida que debe adoptarse son éstas: I.- Que haga cesar sin dilación la guerra civil que está devastando América, y deteniendo los socorros que necesita la España. 2.- Que inspire confianza a los americanos para proceder a una composición en que ellos tienen poco interés y la España mucho, o todo. 3.- Que España esté dispuesta a ceder, de lo que llama sus derechos, todo lo que no se oponga directamente a la unidad de la monarquía española».

Leída hoy esta manifestación de Blanco suena como un grito agónico e inútil.

No obstante, seguirá proponiendo vías pacíficas para la resolución de la cuestión americana y de reconciliación entre las dos partes de un mismo país. En un interesante artículo elaborado con el propósito de explorar las diferentes vías Blanco White compara la política que siguió en América, en circunstancias no muy diferentes, «el monarca más poderoso, y más altivo que jamás se sentó sobre el trono español, Carlos $\mathrm{V}$, que nunca perdonó ni una sombra de desobediencia en Europa» con la de los gobernantes españoles. El emperador disimuló la rebelión de los conquistadores españoles en las tierras del antiguo imperio Inca; una rebelión que puso en jaque su dominio, con el apelativo de disensión; al mismo tiempo, enviaba, en lugar de ejércitos, a diplomáticos «con órdenes positivas de negociar la pacificación». Sabía que su imperio dependía de las riquezas americanas y ello le obligaba a consentir, negociar e integrar. Nada de eso hacen los políticos contemporáneos a Blanco White. La moraleja no deja de mostrar la lucidez del desterrado: «La política de un Carlos V, en medio de su inmenso poder, fue condescender a tiempo por no comprometer su establecida autoridad; la de la Regencia y Cortes de España es comprometer, desde luego, la vacilante que apenas disfrutan». En el único asunto que tenían que hacer política de verdad, en América, cuya dirección «exigía prudencia, combinación, arte, penetración y tino», pero «el orgullo resentido de los españoles» ha originado el peor de los males, pues «los pasos que se han dado hacia lo que llaman conciliación han tenido el efecto contrario, por haber impreso en cada uno de ellos la marca del resentimiento, que era lo primero que debían disimular, si es que no podían prescindir de tenerlo». En este momento, la única solución al conflicto es la mediación de Inglaterra, querida por las autoridades de este país y que, sin embargo, será rechazada por los orgullosos diputados de las Cortes españolas. 
Ya son tiempos de excesos provocados por la situación de guerra civil en América. A pesar de su inicial comprensión, a radicalización de los movimientos emancipatorios en Caracas, en México, en Buenos Aires, etc.,obligará a Blanco White a una mayor equidistancia hasta el punto de que acabará mostrando un menor interés literario y político dejando que los acontecimientos sigan su curso e, incluso, lo que es harto extraño, deseando que el monarca absoluto Fernando VII corrigiera los errores cometidos por las Cortes.

Blanco White, no obstante, vio la independencia de las colonias españolas en América como inevitable. Por eso, junto a la información habitual, sus juicios políticos y sus críticas, incluyó también algunas recomendaciones éticas que las élites de los nuevos países debían tener en cuenta. También en este punto el sevillano aparece como un intelectual lúcido y clarividente.

«La dificultad esencial de constituirse la América española en estados independientes consiste en que la mayor parte de su población no está capaz de tomar parte directa en el gobierno; y a lo que está no puede unirse entre sí para gobernar a la otra. Los blancos son los que la razón indica, y los que naturalmente se presentan para gobernar la América. Las castas y los indios, aunque no les cedan en disposiciones naturales, han estado y están sumergidos en la más profunda ignorancia, y sería el más horrible delirio poner el gobierno en sus manos. Pero, prescindiendo del saber práctico de la casta europea, que por sus circunstancias no puede ser muy notable o extendido, ¿están sus individuos en disposición de formar gobierno firme, sólido y vigoroso, tal que, por su prudencia, su unión y actividad contenga en subordinación a la inmensa masa de los demás habitantes?».

Desgraciadamente, la casta que debía dirigir los destinos de Venezuela y de América no ha usado su gobierno con prudencia y equidad con el objeto de hacer más libres a sus ciudadanos. Pero, «una amarga experiencia lo está demostrando a nuestra vista»: la casta que debiera gobernar se ha dividido en dos partidos y arman a las «otras para degollarse mutuamente. ¿Y qué, vencidos los europeos, quedarían los criollos bastante unánimes para consolidar su gobierno». Y añade: «En ninguna parte del mundo sería más peligroso romper la costumbre de obedecer a un antiguo gobierno que en la América española, porque en ninguna parte del mundo ha habido una población más incapaz de obedecer por razón y convencimiento». De ahí la necesidad de un partido que recomiende «la reconciliación pronta de las Américas con España» para «evitar esta cadena de revoluciones que naturalmente han de verificarse allí a no aplicarse este remedio prontamente».

Por eso, el remedio consiste en satisfacer las reivindicaciones americanas en el seno de la corona de España. «¿A qué aspiran los patriotas americanos? A la libertad e independencia. ¿Y cuál es el objeto de esta libertad e independencia? La riqueza y prosperidad de aquellos países. Luego de dos clases de independencia, la que produzca estos bienes más pronto y con menos riesgo es la que deben elegir los americanos». De esta manera, Blanco White explica al americano que la independencia absoluta ocasiona perjuicios por el mero hecho de generar una guerra con los españoles, conspiraciones entre partidos, disensiones con otras provincias, en fin, disturbios interiores. En cambio, «la independencia moderada, o convenio general de las Américas españolas con la madre patria, bajo la garantía de la Gran Bretaña, y sobre bases de igualdad real de derechos y leyes, ofrece sin tardanza poner fin a las hostilidades en toda América española, a persecuciones y espionaje del interior, a las prisiones y suplicios; ofrece restablecer y conservar los lazos de la subordinación de las clases numerosas y temibles de indios y gente de color, que no son propietarios, y por lo tanto tienen una inclinación vehementemente a la anarquía. Ofrece dejar libre a la industria, por igual y a un tiempo en toda la América; ofrece últimamente amistad con la única potencia marítima que puede proteger el comercio de los puertos de la América española». 
Una especie de confederación internacional entre España y las colonias americanas es lo que cree pertinente Blanco White una vez han pasado dos años del inicio del movimiento revolucionario, se han enquistado y radicalizado las posiciones y la violencia no parece terminar. Sólo así se volvería al cauce normal de una vida social sosegada y se conseguiría la paz necesaria para lograr la prosperidad de las naciones americanas a través del comercio y de la industria. Con más de un siglo de antelación, Blanco White, a la vista de la experiencia de la América inglesa recomienda para la América española lo que el imperio británico experimentará con éxito en el siglo XX: una Commonwealth con sus colonias bajo el gobierno formal de la monarquía británica.

Todo serían beneficios, para Blanco White, en esta unión libre de los ciudadanos americanos con la corona de España. Bajo el gobierno de la monarquía española, los americanos gozarán de los bienes reales a que puede aspirar todo hombre que vive en sociedad: la seguridad de su persona y de sus bienes. Y concluye: «que los dos bienes de que hablo pueden disfrutarse en América sin separarse de la monarquía española no tengo que cansarme en demostrarlo».

\section{VII}

En resumidas cuentas, la figura de Blanco White aparece hoy ante nuestros ojos como un adelantado a su tiempo. Lúcido en la anticipación de los problemas y sus soluciones; crítico con el devenir de los acontecimientos. En sus artículos y ensayos, esbozó un proyecto político que hoy definiríamos como liberal. Cierto es que es su pensamiento evolucionó - desde una postura más jacobina a una posición más moderada por influjo de su estancia inglesa- y se construyó como un pensamiento en acción. Por ello, no debe extrañar que, junto a su lucidez, podamos encontrar excesos retóricos $u$ opiniones contradictorias. Pero ello no debe deslucir la grandeza de su empresa y la bondad de su empeño.

No quisiera terminar mi intervención sin señalar que, en la obra de Blanco White son evidentes unas ideas fuerza que la obsesionarán a lo largo de toda la vida. La más importante y principal es, sin duda, su obsesión por España y su situación de «abatimiento», de secular postración, debida, según su análisis, a la tiranía en el conocimiento impuesta por la Inquisición. Su deseo y esperanza en lograr una España moderna, renovada, a la altura del tiempo que inauguró la revolución francesa fue una constante de su vida y de su obra. 